\title{
فاعلية القنوات الفضائية في نشر ثقافة العمل التطوعي بين الشباب \\ دراسة تطبيقية
}

م. د. د. أفنان محمد شعبان

جا معة بغداد - مركز بحوث السوق وحماية المستهلك

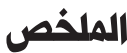

يتناول البحث فاعلية القنوات الفضائية يْ نشر ثقافة العهل التطوعي بين الشباب وهي دراسة

تطبيقية تهلف الىى معرفة مدى ادراك العينة لثقافة العمل التطوعي، وتحديد نوع العلاقة بين برامج القنوات الفضائية وادراك العينة لثقافة العهل التطوعي، ومعرفة نوع العلاقة بين خصائص العينة وتاثير القنوات الفضائية ِِِ اتجاهاتها، والتعرف على مدى العلاقة بين المتفيرات الديهوغرافية للعينة نحو المشاركة فِّ الاعمال التطوعية. واجريت دراسلة ميدانية لعينة من طلبة كليات جامعة بغداد مكونة من ( (10 ) مفردة من الذكور والاناث، وجرى توزيع استمارة استبانة تضمنت مجمومة من الاسئلة التي تختبر الفروض والاهداف الموضوعةة، واستخلم البرنامج الاحصا ئي SPSS لاستخراج البيانات والتكرارات والنسب المئوية والوسط الحسابي والانحراف المعياري واختبـار كاب واختبار بيرسون، وتوصل البحث الى اهم النتائج هي العينة

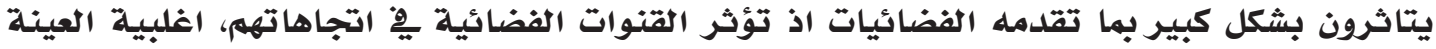
لديهم معرفة بوفهوم ثقافة العهل التطوعي بانها اعمال ونشاطات لا تهاف الى تحقيق الربح، واثبت صحة الفرض بوجود فروق دالة بين المتفيرات الديموغرافية للعينة نحو المشاركة يِّة الاعمال التطوعية، كما اثبت صحة الفرض بوجود علاقة ارتباط دالة بين المتغيرات الديهوغرافية للعينة وتأثير القنوات الفضائية يِّ اتجاها تها، وتم اثبات صحة الفرض بوجود علاقة ارتباط دالة بين مشاهدة برامج القنوات الفضائية وادراك ثقافة العمل التطوعي للى العينة. كالمات همثناهيثة فاعلية، القنوات الفضائية، العمل التطوعي، ثقافة، الشباب.

The effectiveness of satellite channels in spreading the culture of volunteering among youth / applied study

Dr. Afnan Mohammed Shaban

Market Research \& Consumer Protection Center

University of Baghdad

dr.afnan@mracpc.uobaghdad.edu.iq

\section{Abstract}

The study deals with the effectiveness of satellite channels in spreading the culture of volunteer work among young people. It is an applied study aimed 
at understanding the extent to which the sample understands the culture of volunteering, determining the type of relationship between the satellite channels programs and the perception of the sample of the culture of voluntary work and the relationship between the characteristics of the sample and the effect of satellite channels in their directions, And to identify the relationship between .the demographic variables of the sample and to participate in voluntary work A sample study was conducted for students of faculties of the University of Baghdad, consisting of (150) single male and female. A questionnaire was distributed which included a set of questions that test the hypotheses and objectives set. The statistical program used spss to extract data, frequencies, percentages, arithmetic mean, standard deviation, And the research reached the most important results are the sample are greatly influenced by the satellite channels as satellite channels affect their directions, the majority of the sample have knowledge of the concept of the culture of volunteer work as non-profit activities and activities, and proved the validity of the hypothesis The validity of the hypothesis was proved by the existence of a significant correlation between viewing the satellite channel programs and understanding the culture of voluntary work in the sample. In addition, there is a significant correlation between the . demographic variables of the sample and the participation in voluntary work Keywords

Effectiveness, Satellite Channels, Volunteerism, Culture, Youth

المقدمة

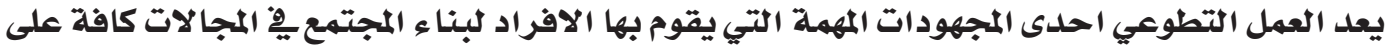

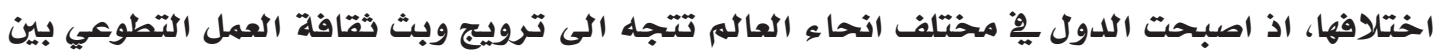
افراد مجتمعها لتكون حافزا لتطوير مجتمعات التها لتهم.

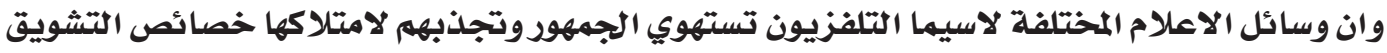

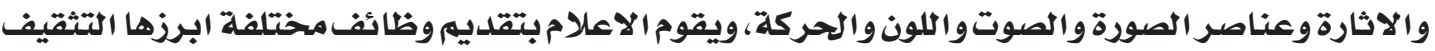

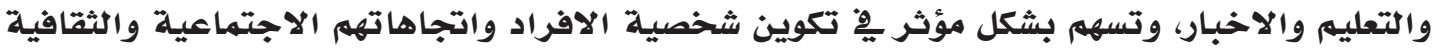

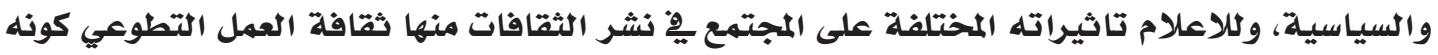

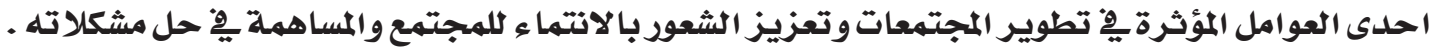

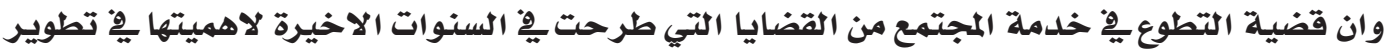

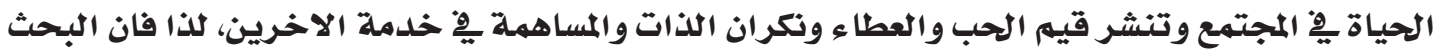

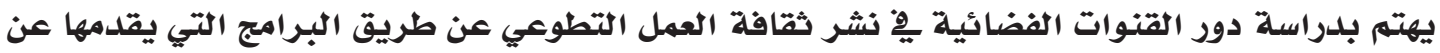

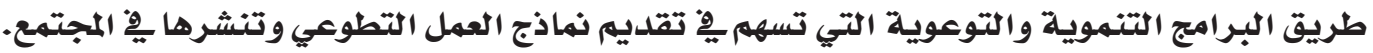


وأجريت دراسة ميدانية على عينة من الجمهور، وعليه تكونت هيكلية البحث من المباحث الآتية ؛

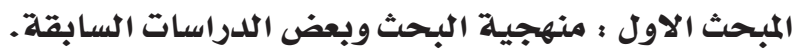

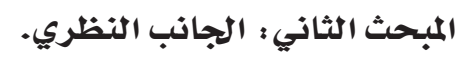

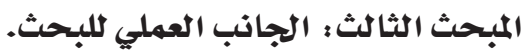

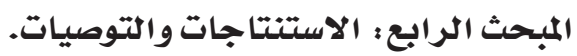

\section{المبحث الأول: منهبية البحث وبعض الدراسات السابقة}

$$
\text { أو أو : مشكلهة البحثة البحث }
$$

ارتبط العهل التطوعي بالممارسات والاعمال الانسانية التي تهاف الى تنهية المجتهمع، وان مجتمعاتنا بحاجة كبيرة الى نشر ثقافة العمل التطوعي عبر وسائل الاعلام لاسيما القنوات الفضائية، وان نقص الاهتهام بمهارسلة الاعمال التطوعية وعلم استيعاب مفهومها يعد مشكلة تحتاج الى التصدي لها لها

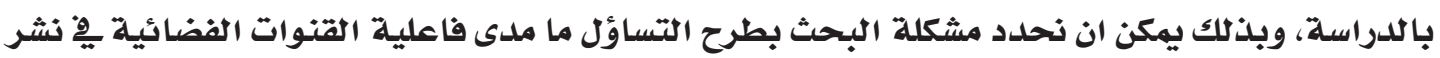
ثقافة العمل التطوعي بين الشباب؟ ولئ.

اسئلة الدراسة

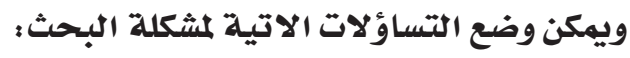
- ما الدور الذي تقوم به القنوات الفضائية التلفزيونية ـِّن نشر ثقافة العمل التطوعي من مفهوم الشباب؟ - ما مدى تعرض الشباب للبرامج التي تقدم العهل التطوعي يِّ الفضائيات؟

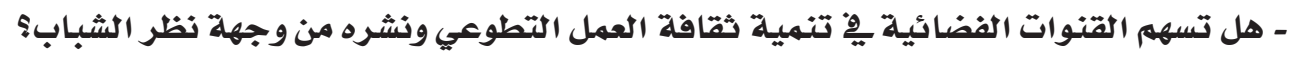

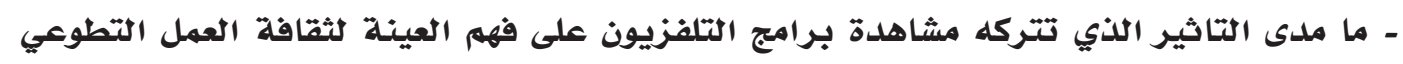

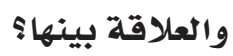
ـ هل تؤثر خصائص العينـة نحو المشاركة فِ إلاعمال التطوعيةه؟.

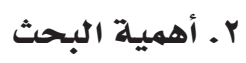

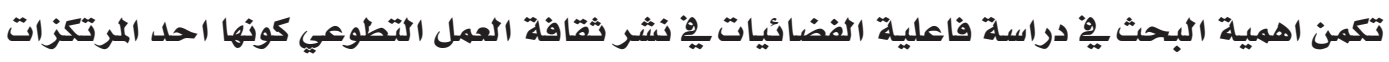

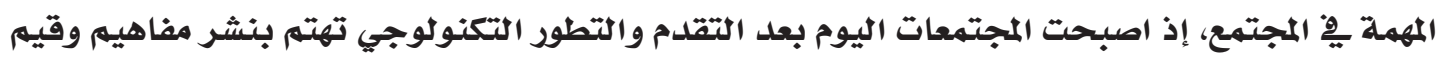

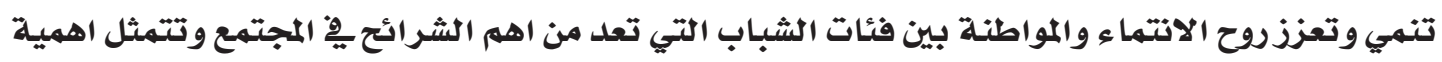

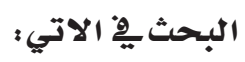
ـ ان موضوع العهل التطوعي يعد من الموضوعات التي يجب ان تحظى باهتهام الحكومات والمؤسسات

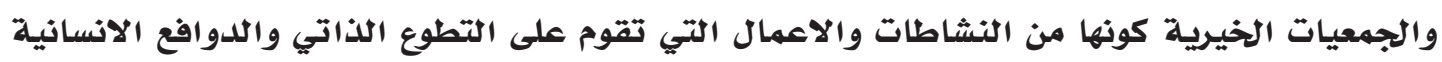

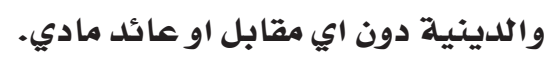

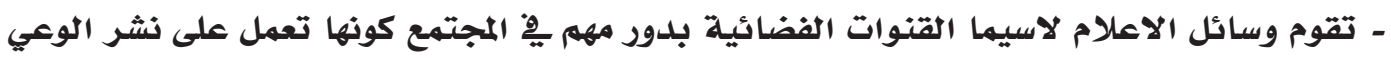

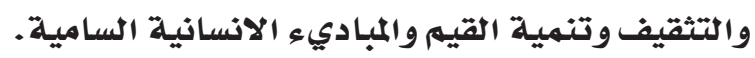


- يعد الشباب ثروة وطنية مهمة لذا تركز الدراسة على معرفة مستوى الوعي والادرات للدى الشباب

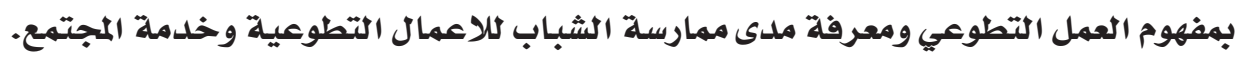

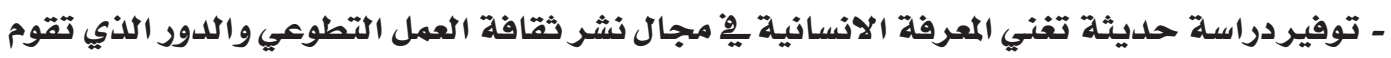

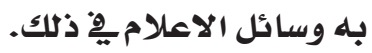
- يختص البحث بلدراسلة دور القنوات الفضائية وفاعليتها يِّ تنمية ثقافة العمل التطوعي من منطلق

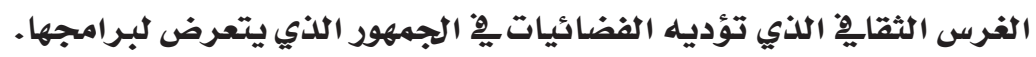

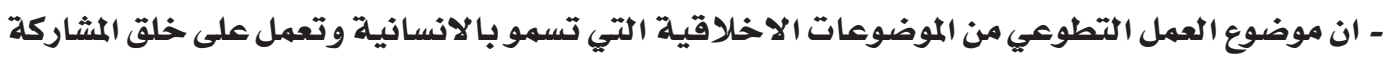

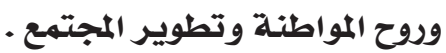

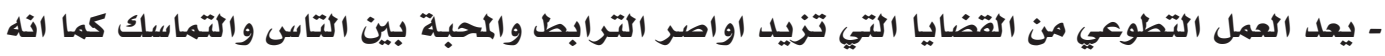
يشيع روح التعاون للدى الافراد.

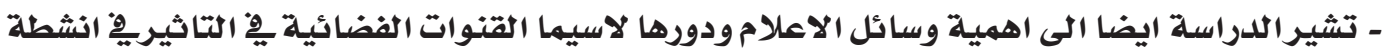

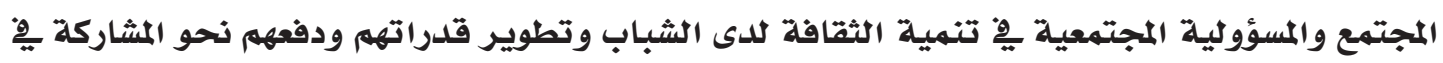

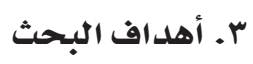

ا - معرفة مدى ادراك العينة الثقافة العهل العلمات التطوعي.

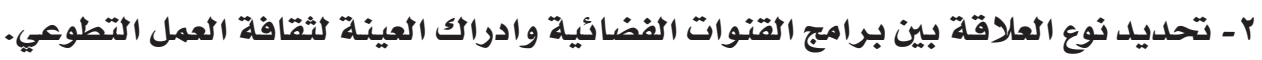

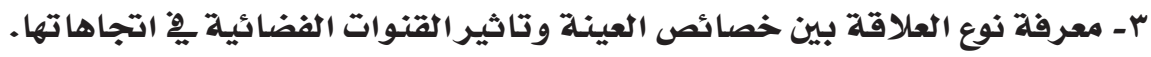

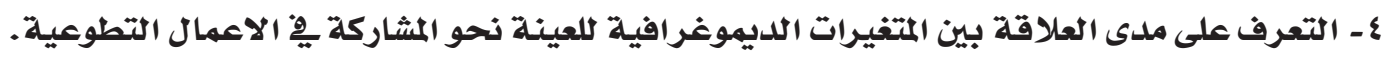

$$
\text { ع. فرضيات البحث }
$$

ـ توجل علاقة ارتباط دالة بين مشاهدة برامج القنوات الفضائية وادرات العينة لثقافة العمل التطوعي. ـ توجل علاقة ارتباط دالة بين المتغيرات الديهوغرافية للعينة وتأثير القنوات الفضائية يِ اتجاها تها ـ توجد فروق دالة بين المتغيرات الديهوغرافية للعينة نحو المشاركة يِّاء الاعمال التطوعية.

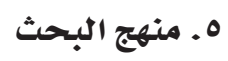

يعد البحث من البحوث الوصفية التي تستهدف التعرف على الاوصاف الدقيقة للظاهرة، ويعتمد

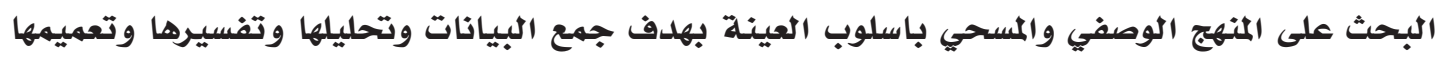

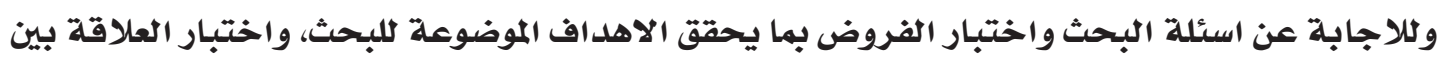

$$
\text { المتتغيرات المختلفة. }
$$




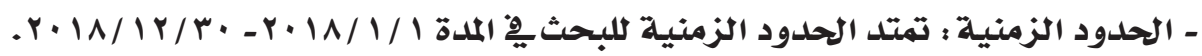

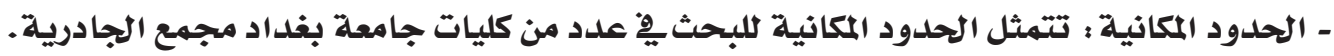

\section{V . مجتمع البحث وعينته}

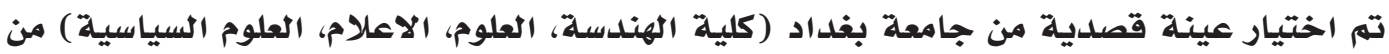

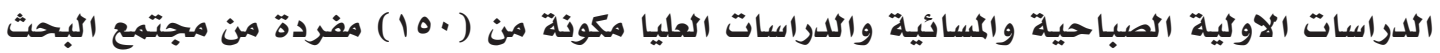

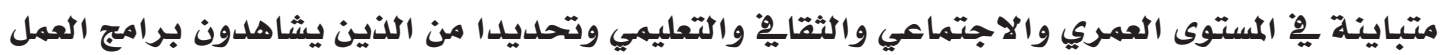

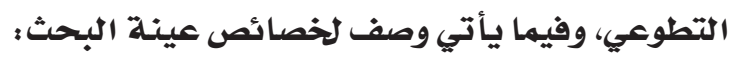

جدول (1 ) : يبين خصائص العينة

\begin{tabular}{|c|c|c|c|}
\hline النسبة المئوية & العدد & الفئات & التفاصيل \\
\hline$\% \varepsilon r, v$ & $7 \varepsilon$ & ذكور & \multirow[t]{2}{*}{ النـــوع } \\
\hline$\% \Delta V, r$ & ז & اناث & \\
\hline$\%$ rA & or & $r Y-11$ & \multirow[t]{4}{*}{ الفئات العمرية } \\
\hline$\%$ \% & 79 & $r v-r r$ & \\
\hline$\% 17$ & $r \varepsilon$ & MI-rA & \\
\hline- & لا يوجد & rr فاكثر & \\
\hline$\% 1 r, v$ & 19 & الاولى & \multirow[t]{5}{*}{ المرحلة الدراسية } \\
\hline$\% \backslash \wedge, \vee$ & rA & الثانية & \\
\hline$\%$ \% & rA & الثالثة & \\
\hline r, rr\% & 0. & الرابعة & \\
\hline$\% 1$. & 10 & دراسات عليا & \\
\hline$\% \varepsilon \cdot, v$ & 71 & انساني & \multirow[t]{2}{*}{ التخصص } \\
\hline$\%$ & 19 & & \\
\hline
\end{tabular}

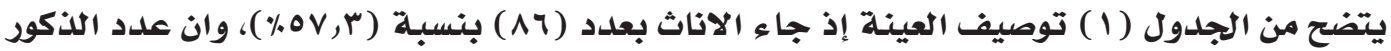

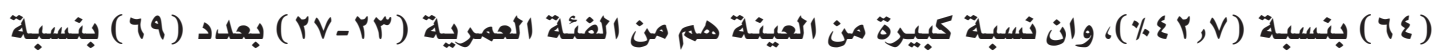

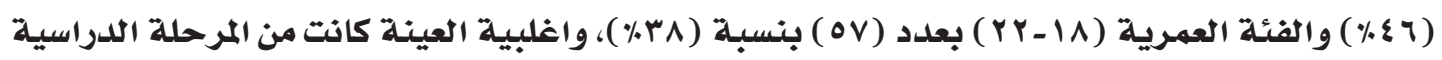

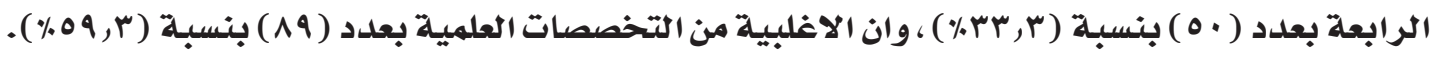

1. اداة البحث تم استخدام استمارة استبيان اداة البحث بغرض تحقيق الاهداف البحث والمتكونة من ثلاثة محاور

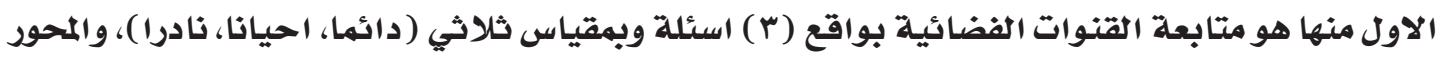

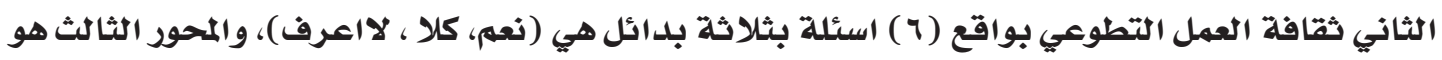

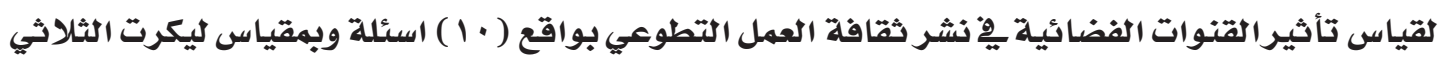

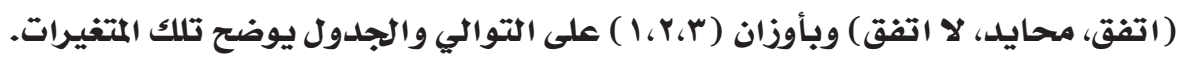




\begin{tabular}{|c|c|c|}
\hline المتغير التابع & المتغيرات الوسيطة & المتغير المستقل \\
\hline \multirow{3}{*}{ نشر ثقافة العهل } & المتغيرات الديموغرفية & \multirow[t]{3}{*}{ فاعلية القنوات الفضائية } \\
\hline & (النوع، العهر، المرحلة & \\
\hline & الدراسية، التخصص) & \\
\hline
\end{tabular}

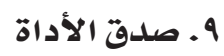

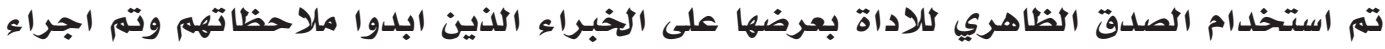

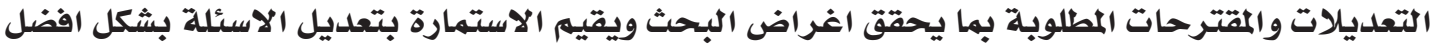

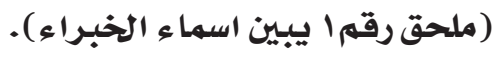

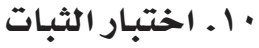
اجري اختبار ثبات التحليل باستخدام معامل الثبات (الفاكرونباخ) وكانت نسبته تتراوح بين ( و ه, • )

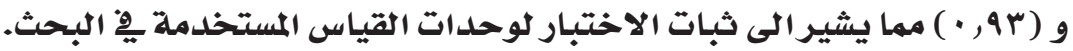

ا Iا المصطلحات الاجرائية للبحث

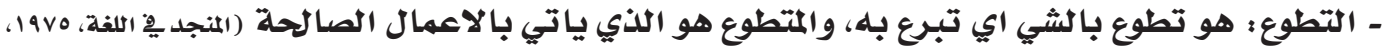

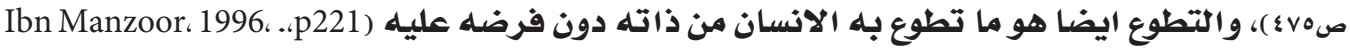

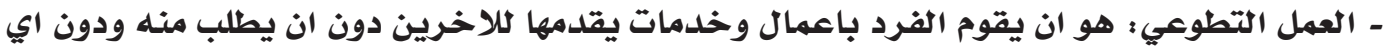

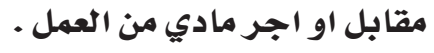

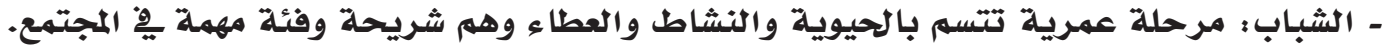

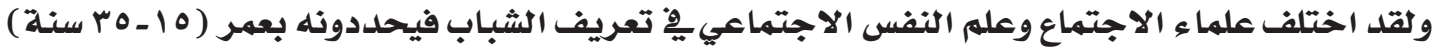
او يحلدونه بمرحلة نهو تكتمل فيه اعضاء الانسان وبنيته (AL-Saate،2003،p15).

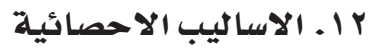

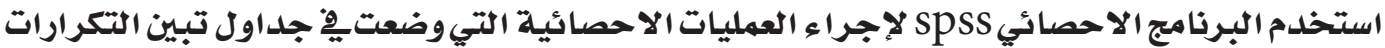

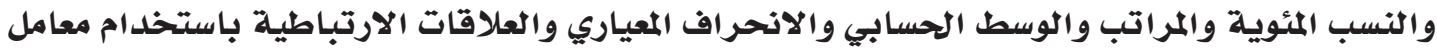

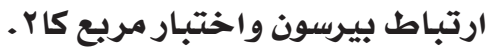

ثانيا : بعض الدراسات السابقة

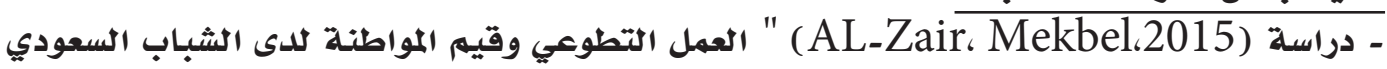

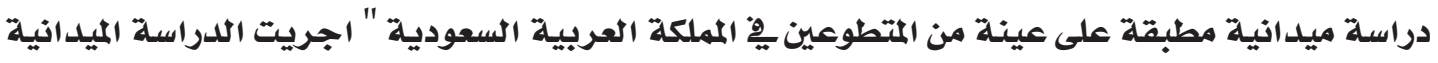

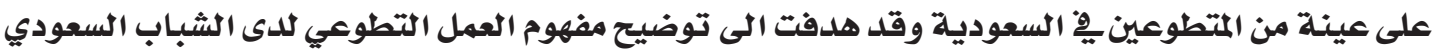

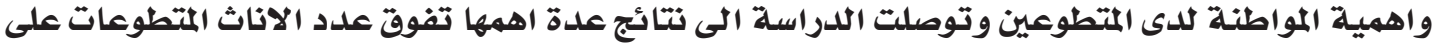

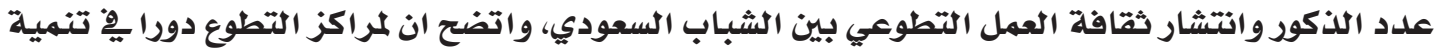

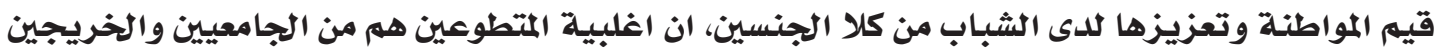


وحملة شهادة الماجستيروالدكتوراه، وخرجت الدراسة بوضع توصيات بضرورة تنمية التطوع للى طلبة

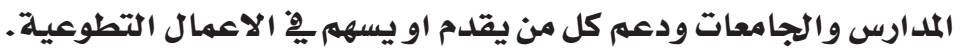

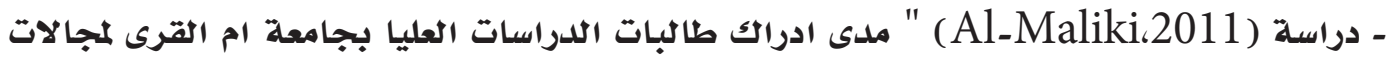
العمل التطوعي للمرأة فِ المجتهع السعودي" اجريت دراسة ميدانية على عينة من طالبات الدراسات

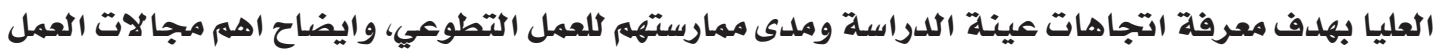

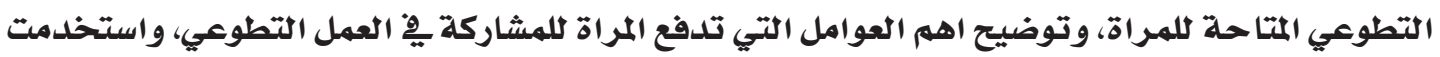

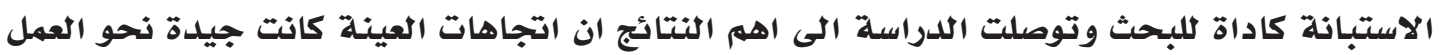

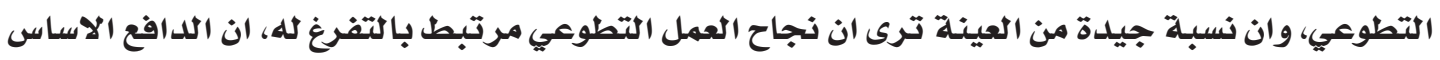

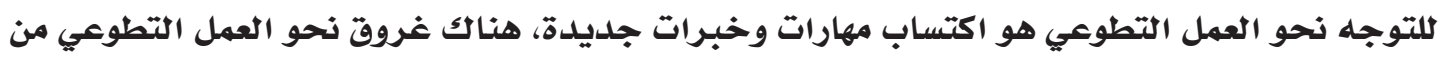

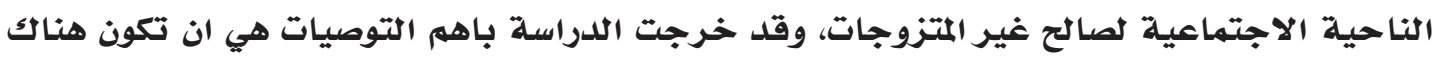

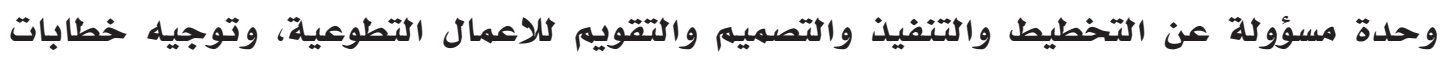

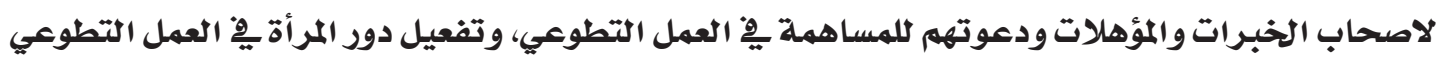

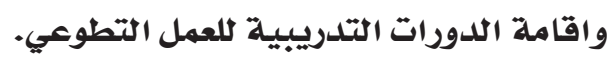

\section{المبحث الثاني : الجانب النظري البحث}

\section{ترتبط هذرية الغرب الثقإِ}

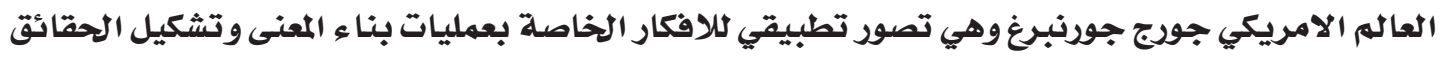

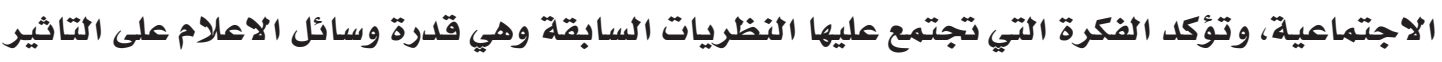

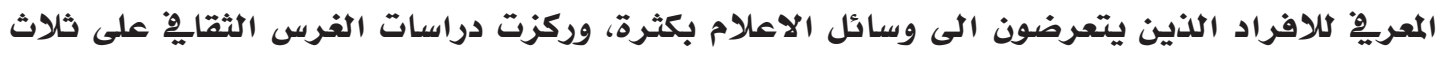

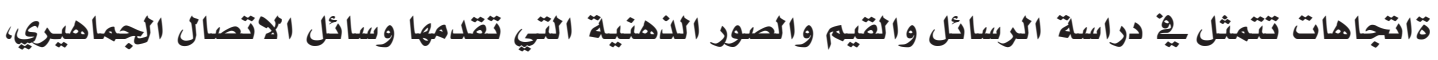

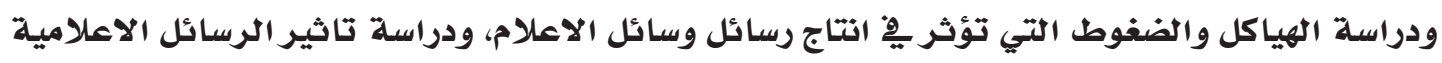

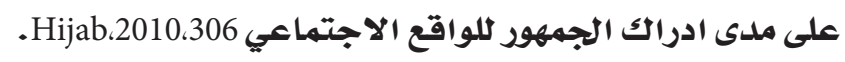

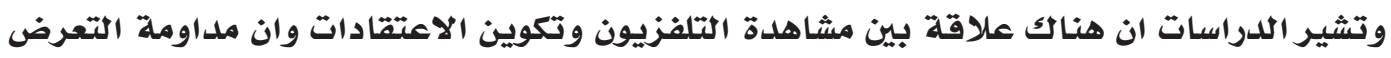

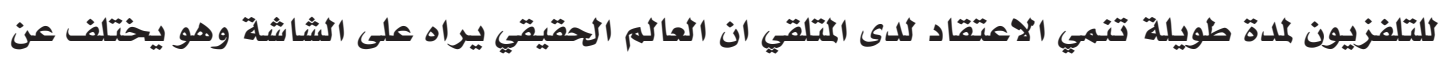

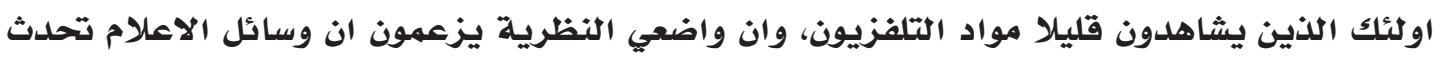

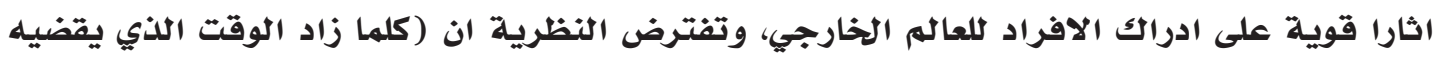

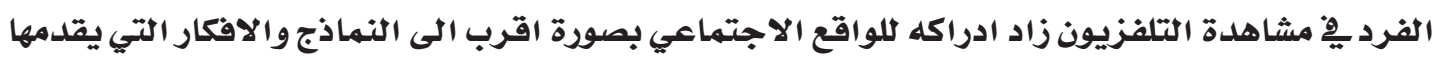

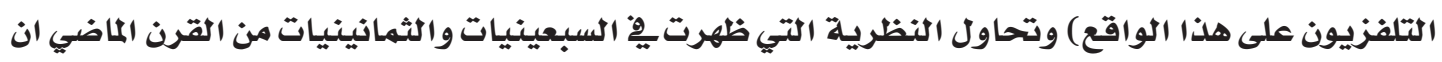
تفسر الاثار الاجتهاعية والمعرفية لوسائل الاعلام لاسييما التلفزيون (Makkawi،2000،P112-114).

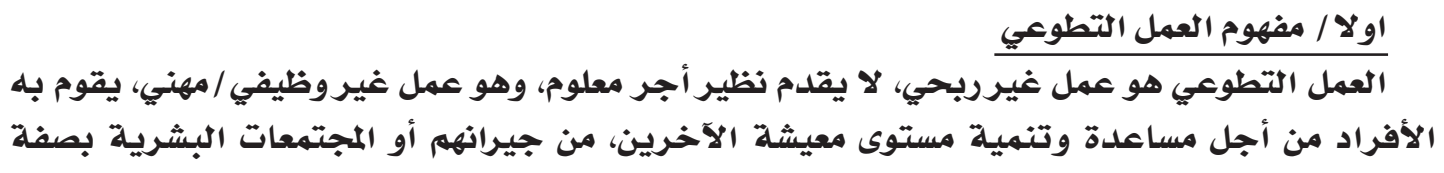


مطلقة (Hussein،2001).

والتطوع هو البذل والتضحية من اجل الاخرين وهو يقوم على معان سامية واهداف خيرة، ويشمل

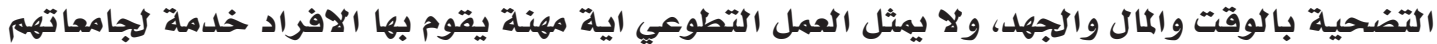

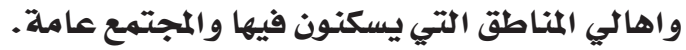
وهناك الكثير من الأشكال للعهل التطوعي منها مشاركات تقليدية لمصلحة اشخاص الشاص او مجتمع وتقديم

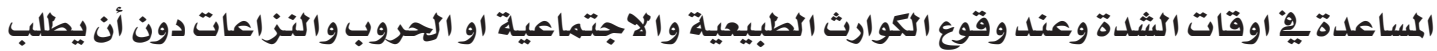
منهم المساهمة انها هورد فعل ذاتي دون توقع نظير مادي لذأك العهل، بل النظير هو سعادة ورضا عند رفع

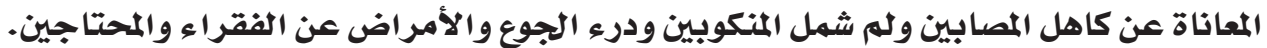
ويكون العهل التطوعي عبارة عن جهود انسانية نابعة من الرغبة والدافع الذاتي على شكلين الفردي وهو يقوم به الفرد من تلقاء نفسه بدافع اخلاقي واجتماعي وديني، اما العهل المؤسسي فهو ما تقوم به المؤسسات الخيرية والتطوعية والتي تستقطب عددا كبيرا من فئات الشباب المتطوعين وتقوم بالاشراف على الاعمال مباشرة وهي اما تا بعة للحكومات او تكون بجهود ذاتية من الافراد (AL-Shahrani، 2016،P10).

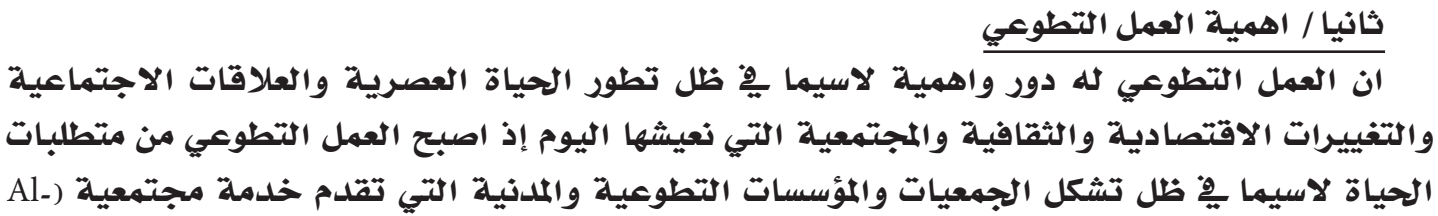
.(Naim، 1999،P5

وتاتي اهمية العمل التطوعي عن طريق تقليه رفع مستوى الخلمات واكمال العهل الذي تقلمهه المؤسسات الحكومية، وتادية خلدمات لا تقوم بها المؤسسات لظروف معينة، وتقديه خلدمات جلديدة ومفيدة للمجتهع (Al-Juhani، 2010،445)

ويلخل العمل التطوعي ضمن المجالات الاجتماعية على اختلافها التربوية والتعليمية والصحية والطبية والدينية ورعاية كبار السن والشباب والاطفال وغيرها من المجالات المجتمعية الاخرى.

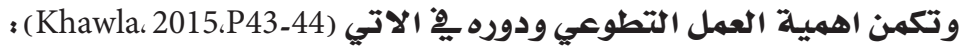
ـ الجانب الاقتصادي : يساهم العهل التطوعي يخ توفير المبالغ المالية التي تتطلبها بعض الخدمات المجتمعية وتحتاج الى المال. - الجانب الامني: ان العمل التطوعي له دور يِّ تنهية وغرس روح العطاء لدى الشباب وتعزيز قيم الانتماء والاحساس بالمسؤولية، وتنمية مهاراتهم وقدراتهم وتعزيز القيه التربوية والاجتماعية

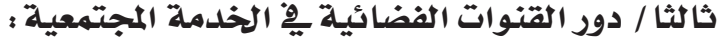

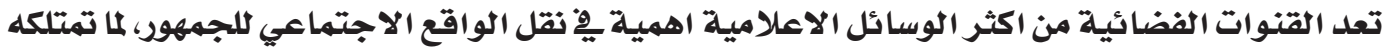
من خصائص الانتشار الواسع والقدرة على الاستقطاب والاستحواذ واستخدام الصورة والصوت وتوافر عناصر الابهار، ويخاطب جميع شرائح المجتهع على اختلاف مستوياتهم للتاثير فِ ارائهم ومعتقداتهم 
ويؤدي التلفزيون دورا خطيرا ومهما ِِ حياة المجتهعات على الرغم من عده وسيلة ترفيه وتسلية

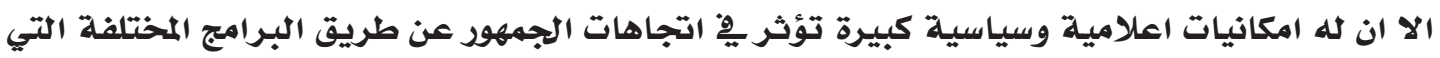

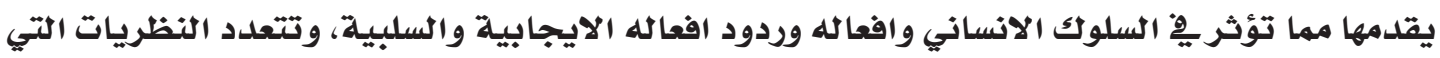

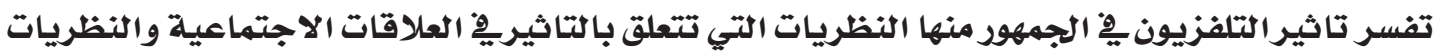
المؤثرة على العقل والفكر وغيرها من النظريات الاعلامية (Shahab Alddeen، 2017، P59-60).

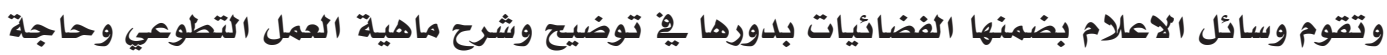

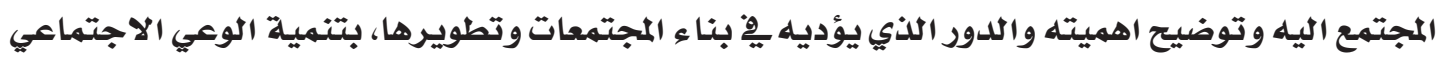

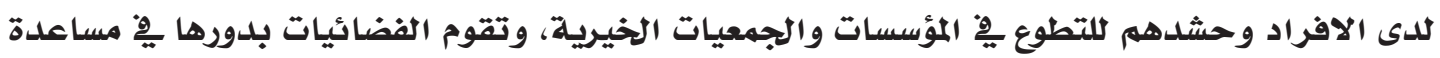
الجهات التطوعية يِّ استقطاب المتطوعين بوصفهم عناصر مفيدة للعهل يِّ هذه المؤسسات، وتكون وسائل الاعلام الداخلية جزءا من وسائل الاعلام العامة عن طريق تزويلةها بالاروقام والاحصدائيات والتقارير

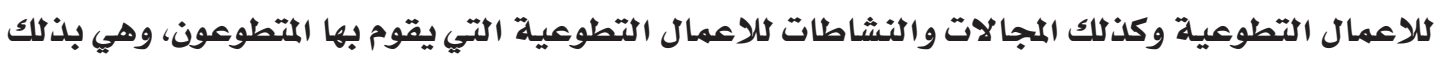
تظهر اهميتها يِّ العمل التطوعي لدى الشباب عن طريق (AL-Shahwan،2017،P27).

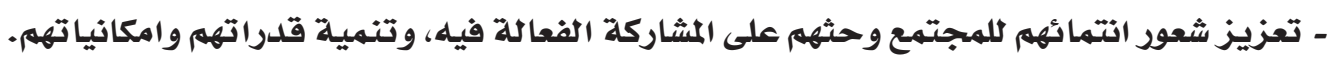

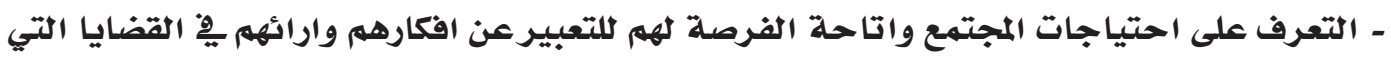

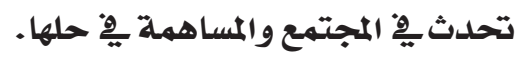

نماذج برامح العمل التطوعي يِ القنوات الفضائية ؛

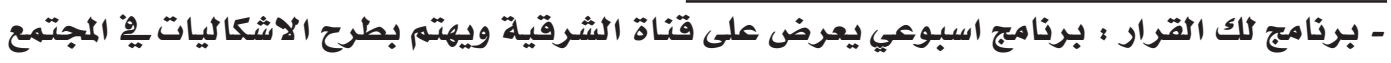
العراقي، ويشارك فيه الشباب عن طريق تقليه المساعدة للناس والقيام باعمال تطوعية تخلدم ابناء المجتهع - برنامج شباب الخير : برنامج يعرض على قناة العاصمة المصرية ويطرح قضايا المجتمع المصري

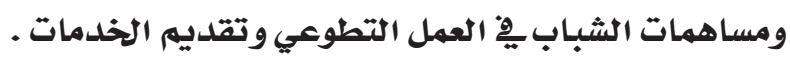

\section{المبحث الثالث : الجانب العملي البحث}

$$
\text { او - ملى متابعة متابعة القنوات الفضواتية : }
$$

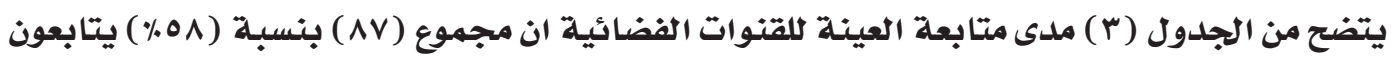

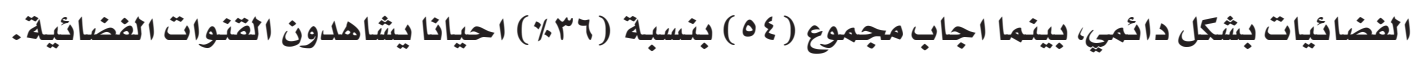




\section{جدول (r) يبين مدى متابعة العينة للقنوات الفضائية}

\begin{tabular}{|c|c|c|}
\hline النسبة المئوية & التكرارات & مدى متابعة القنوات الفضائية \\
\hline$\% .01$ & $\wedge \vee$ & 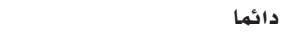 \\
\hline$\%$ & o & احيانا احيا \\
\hline$\%$ & 9 & 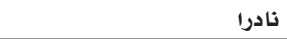 \\
\hline$\% 1 \ldots$ & 10. & المجموع \\
\hline
\end{tabular}

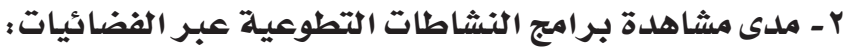

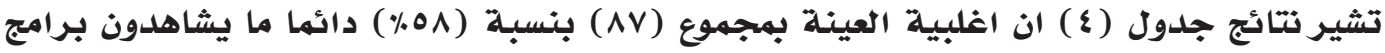

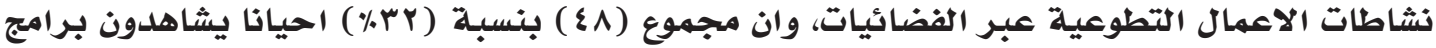

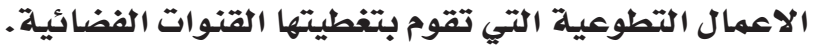

\section{جدول ( ع ) يبين مدى مشاهدة برامج النشاطات التطوعية عبر الفضائيات}

\begin{tabular}{|c|c|c|}
\hline النسبة المئوية & التكرارات & مدى مشاهدة برامج النشاطات \\
\hline$\% 01$ & $\wedge \vee$ & دائما \\
\hline \% & $\varepsilon \wedge$ & احيانا \\
\hline$\% 1$ & 10 & ن \\
\hline$\% 1 \ldots$ & 10. & المجموع \\
\hline
\end{tabular}

r- ملدى اعتقاد المبحوثين ان القنوات الفضائية تؤثر فِ اتجاهات الناس ؛

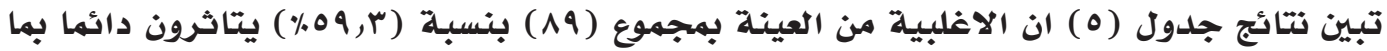

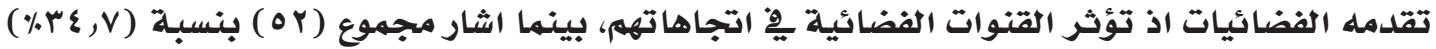

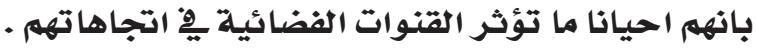

جلدول (0) يبين مدى اعتقاد المبحوثين ان القنوات الفضائية تؤثر ِِّ اتجاهات الناس

\begin{tabular}{|c|c|c|}
\hline النسبة المئوية & التكرارات & مدى تاثير القنوات الفضائية ِ2 \\
\hline$\% .09, r$ & 19 & دائما \\
\hline$\% r \varepsilon, v$ & or & احيانا \\
\hline$\% 7$ & 9 & ن \\
\hline$\% 1 \ldots$ & 10. & المجموع \\
\hline
\end{tabular}

$$
\text { ثانيا / ثقافة العمل التطوعي : المعرفة بان العمل التطوعي ونشاطاته غيرربحي: }
$$

تشير النتائج فِ جدول (7) ان نسبة كبيرة من العينة لديهم معرفة بهفهوم ثقافة العمل التطوعي بانها

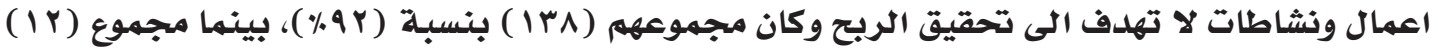
بنسبة (1٪) اجابوا انهم لا يعرفون ان العمل التطوعي ونشاطاته غيرربحي. 
جدول (7 ) يبين مدى معرفة العينة ان العمل التطوعي ونشاطاته غيرربحي

\begin{tabular}{|c|c|c|}
\hline النسبة المئوية & التكرارات & التطوعي ونشاطاته غيرفة العينة ان العمل \\
\hline$\% 9 r$ & IrA & نعم \\
\hline - & - & كل2 \\
\hline$\% \wedge$ & ir & لا اعرف \\
\hline$\% 1 \ldots$ & 10. & المجموع \\
\hline
\end{tabular}

Y - معرفة ان العمل التطوعي يهدف الى مساعدة الاخرين وتحسين معيشتهم وتقديه خدمة مجتهعية :

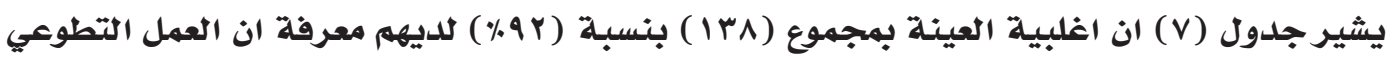

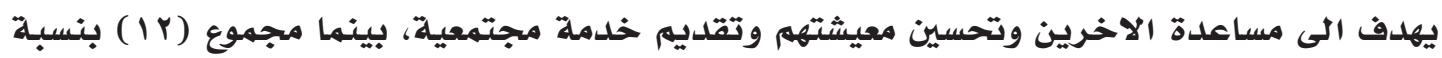

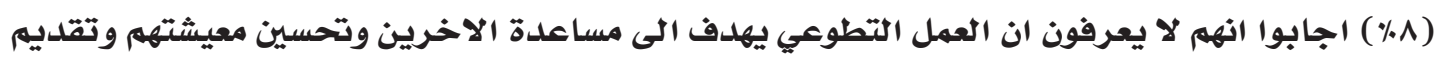

خلممة مجتمعية.

جلدول (V) يبين ملى معرفة ان العمل التطوعي يهدف الى مساعدة الاخرين

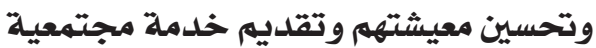

\begin{tabular}{|c|c|c|}
\hline النسبة المئوية & التكرارات & 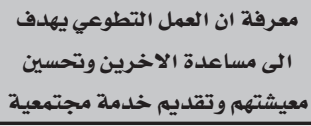 \\
\hline$\% 9 r$ & IrA & نعم \\
\hline- & - & كلا \\
\hline$\% 1$ & ir & لا اعرف \\
\hline$\% 1 \ldots$ & 10. & المجموع \\
\hline
\end{tabular}

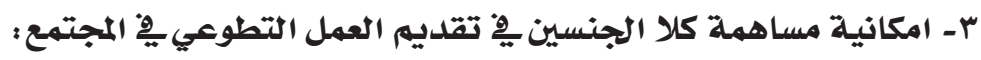

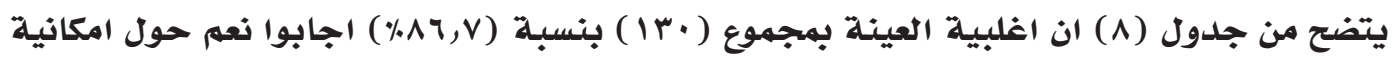

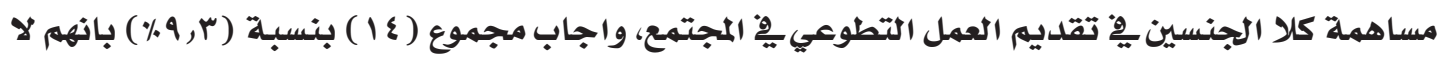

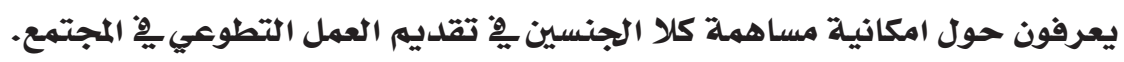

جدول (1) يبين امكانية مساهمة كلا الجنسين فِ تقديم العمل التطوعي فِ المجتهع

\begin{tabular}{|c|c|c|}
\hline النسبة المئويـة & التكرارات & تقديم العمل التطوعي مساهمة كلا الجنسين بـ المجتمع \\
\hline$\% \wedge \uparrow, \vee$ & ir. & تعم \\
\hline$\% \varepsilon$ & 7 & كلا \\
\hline$\%, 4, r$ & $1 \varepsilon$ & لا اعرف \\
\hline$\% 1 \ldots$ & 10. & لمجموع \\
\hline
\end{tabular}

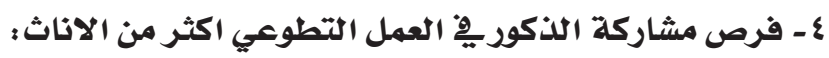

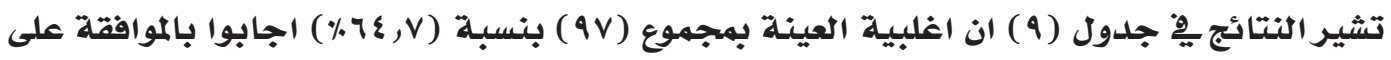




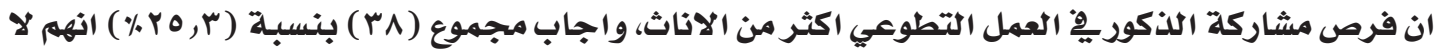

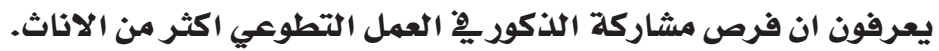

جدول (4) يبين فرص مشاركة الذكور يِّ العمل التطوعي اكثر من الاناث

\begin{tabular}{|c|c|c|}
\hline النسبة المئوية & التكرارات & فرص مشاركة الذكور ِِّ العمل التطوعي اكثر من الاناث \\
\hline$\%\urcorner \varepsilon, \vee$ & $9 \mathrm{~V}$ & نعم \\
\hline$\% 1$. & 10 & كلا \\
\hline$\%$ Y,$r$ & rs & لا اعرف \\
\hline$\% 1 \ldots$ & 10. & المجموع \\
\hline
\end{tabular}

ع - محلدودية الانشطة التوعية التي تشارك فيها الاناث مقابل انشطة الذكور:

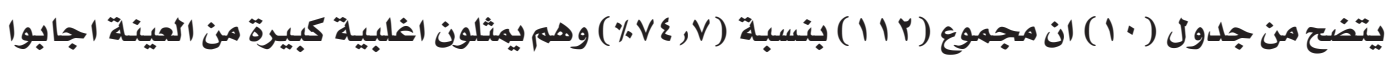
نعم عن محلدودية الانشطة التطوعية التي تشارك فيها الاناث مقابل انشطة الذكور، واجاب مجموع ( م (r) ) بنسبة ( • r ) بانهم لا يعرفون عن محدودية الانشطة التطوعية التي تشارك فيها الاناث مقابل انشطة النكور.

جلول ( • 1 ) يبين محلدودية الانشطة التطوعية التي تشارك فيها الاناث مقابل انشطة الذكور

\begin{tabular}{|c|c|c|}
\hline النسبة المئوية & التكرارات & تشارك فيها الاناث مقابل الشطة التوعية التي الذكور \\
\hline$\% \vee \varepsilon, v$ & $11 r$ & نعم \\
\hline$\% 0, r$ & $\wedge$ & كلا \\
\hline$\%$ r. & $r$. & لا اعرف \\
\hline$\% 1 \ldots$ & 10. & المجهوع \\
\hline
\end{tabular}

ه - يبين مشاركة العينة فيج الاعمال التطوعية ؛ يتضح من نتائج جدول (1 1 ) ان نسبـة كبيرة من العينـة اجابوا بانهم له يشاركوا بشكل فعلي يِّ الاعمال

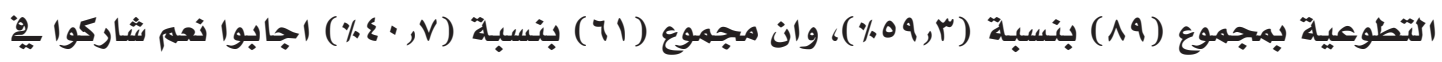
الاعمال التطوعية.

جلدول (11) يبين مشاركة العينة فِ الاعمال التطوعية

\begin{tabular}{|c|c|c|}
\hline النسبة المئوية & التكرارات & يبين مشاركة العينة يِ الاعمال \\
\hline$\% \varepsilon \cdot, v$ & 71 & نعم \\
\hline$\% 09, r$ & 19 & كل2 \\
\hline$\% 1 \ldots$ & 10. & المجموع \\
\hline
\end{tabular}

ثالثا / دور القنوات الفضائية ـِ نشر ثقافة العمل التطوعي:

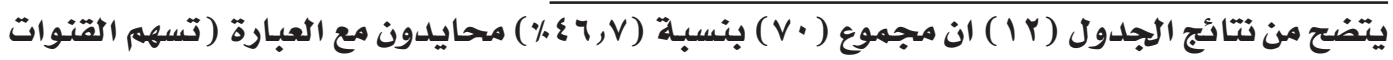

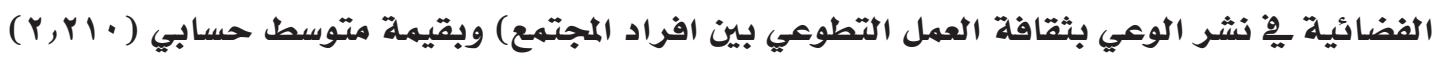


وهي اعلى من الوسط الفرضي (Y) مها يشير الى شلدة الاتفاق وقيمة الانحراف المعياري (VY, (•) )،

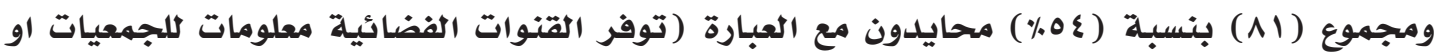

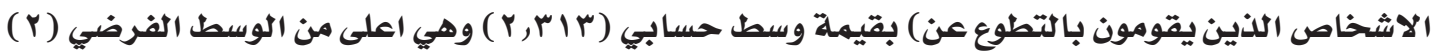

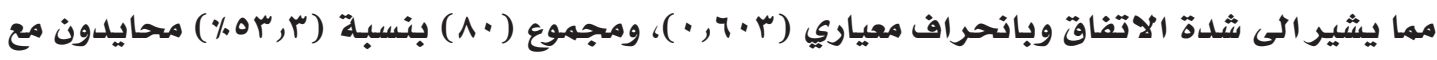

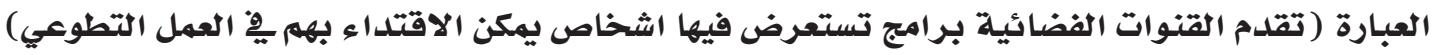

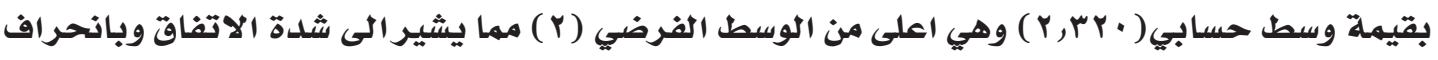

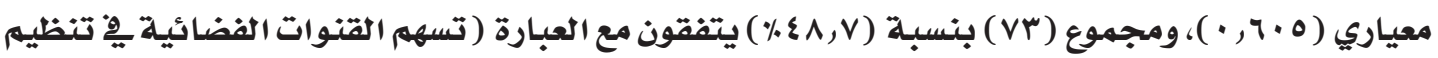

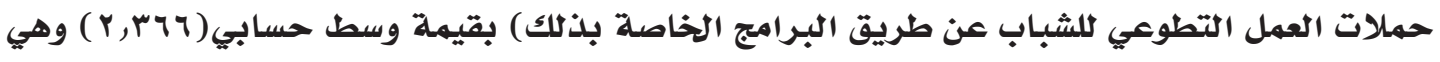

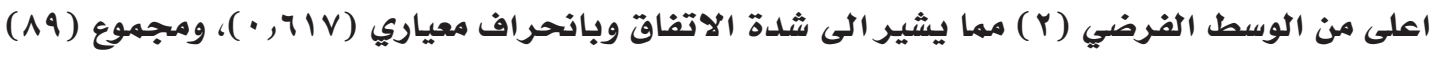

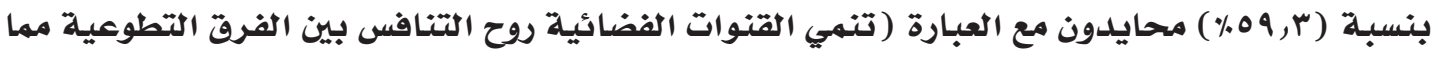

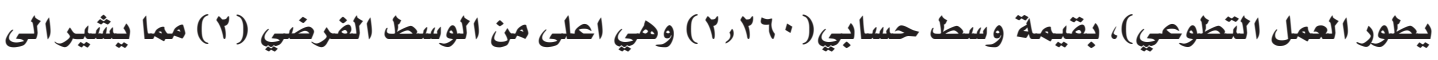

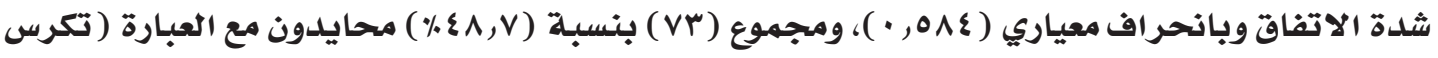

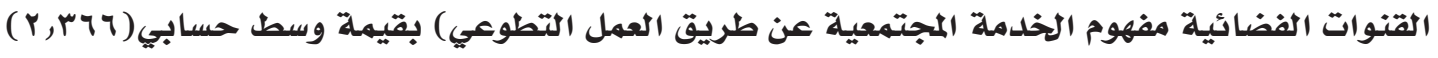

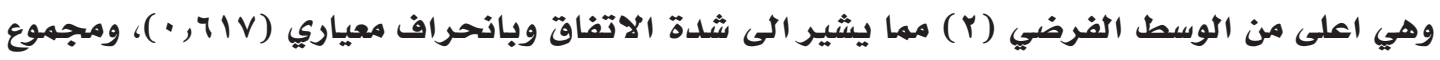

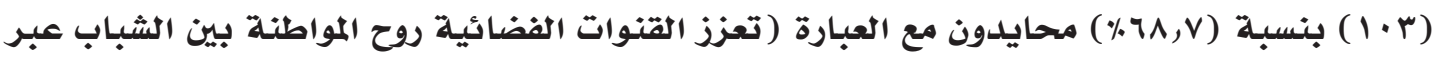

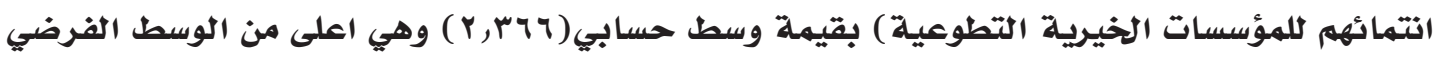

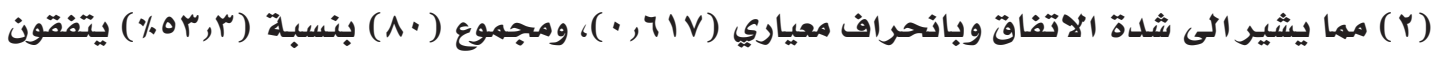

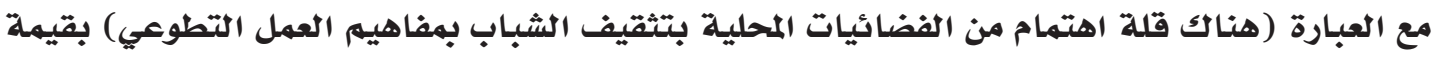

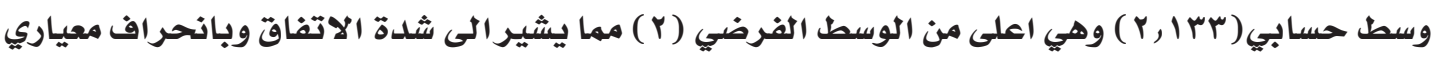

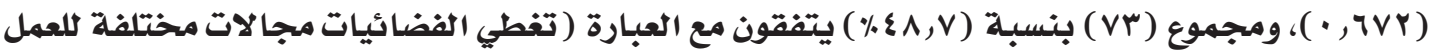

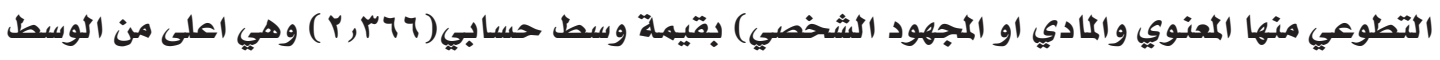

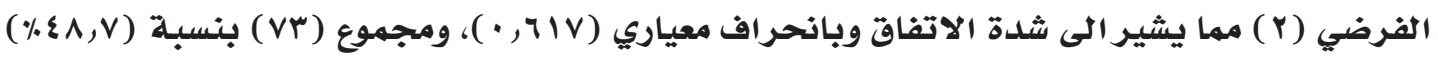

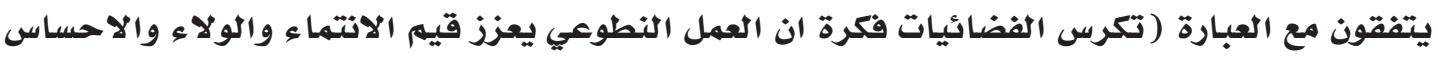

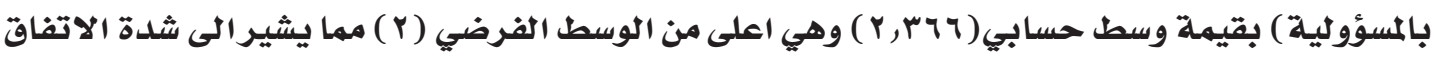

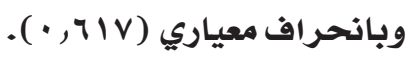


جلدول (Y I ) يبين اتفاق العينـة مع فاعلية القنوات الفضائية فِ نشر ثقافة العهل التطوعي

\begin{tabular}{|c|c|c|c|c|c|c|c|c|c|}
\hline \multicolumn{2}{|c|}{ الانحراف المعياري } & \multicolumn{2}{|c|}{ محايــد } & \multicolumn{2}{|c|}{ لا اتفـق } & \multirow{2}{*}{\multicolumn{2}{|c|}{ اتفــق }} & \multirow[t]{2}{*}{ العبارات } & ت \\
\hline & & & & & & & & & \\
\hline •,VYr & $r, r l$. & $\%, r \cdot, v$ & r & $\%$ \% , V & $v$. & $\% r r, V$ & $\varepsilon 9$ & التطهم القنوات الفضائية ِِِ نشر الوعي بثقافة العمل & 1 \\
\hline r, r.r & $r, r i r$ & $\% v, r$ & 11 & $\%$. \& & $\wedge 1$ & $\% r \Lambda, v$ & $0 \wedge$ & 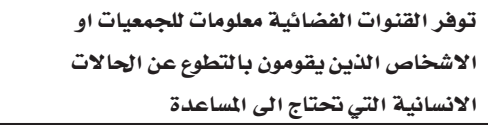 & r \\
\hline$\cdot, 7.0$ & $r, r r$. & $\% \vee, r$ & 11 & r & $\wedge$. & $\% r q, r$ & 09 & القخدم القنوات الفضائية برامج تستعرض فيها & $r$ \\
\hline$\cdot, \pi / v$ & צדצז,r & $\% \vee, r$ & 11 & $\% \varepsilon \varepsilon$ & 77 & $\%$ \%,$\vee \vee$ & vr & تسهم القنوات الفضائية ـِّ تنظيم حملات العمل & $\varepsilon$ \\
\hline$\cdot, 0 \wedge \varepsilon$ & r,Yq. & $\% v, r$ & 11 & $\%$ & 19 & $\% r r$ & 0. & تلتمي القنوات الفضائية روح التنافس بين الفرق & 。 \\
\hline$\cdot, \pi \mid v$ & r,ז & $\% v, r$ & 11 & $\%\{\wedge, \vee$ & $v r$ & $\% \varepsilon \varepsilon$ & 77 & تكرس القنوات الفضائية مفهوم الخدمة المجتمعية & 7 \\
\hline$\cdot, \pi \mid v$ & צדיז,r & $\% v, r$ & 11 & $\% \neg \Lambda, \vee$ & $1 \cdot r$ & $\% r \varepsilon$ & rq & 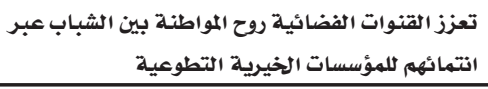 & $v$ \\
\hline - TVY & r,Irr & $\% 17, v$ & ro & $\% \mu$. & \&o & $\%$ & $\wedge$. & 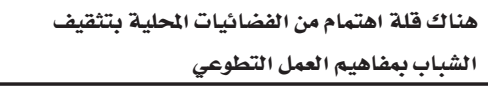 & $\wedge$ \\
\hline$\cdot, \pi \mid v$ & צדיז,r & $\% v, r$ & 11 & $\% \varepsilon \wedge, \vee$ & $v r$ & $\% \varepsilon \varepsilon$ & 79 & منها المعنوي الفضائيات مجالات مخت مختلفة للعمل التطوعي & 9 \\
\hline$\cdot, \pi 1 V$ & צדוז,r & $\% \vee, r$ & 11 & $\% \varepsilon \wedge, \vee$ & vr & $\% \varepsilon \varepsilon$ & 77 & تكرس الفنتماء والئيات فكرة ان العمل النطوعي يعزز قيم الاحساس بالمسؤولية & 1. \\
\hline
\end{tabular}

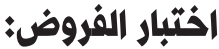

ا - توجد فروق دالة بين المتغيرات الديموغرافية للعينة نحو المشاركة يِّا الاعمال التطوعية.

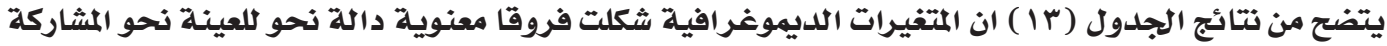

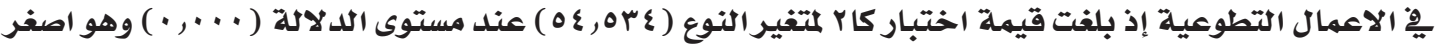

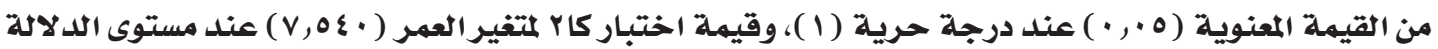

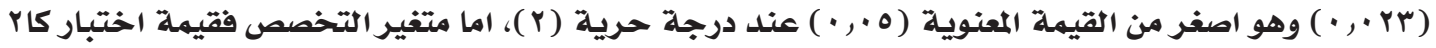

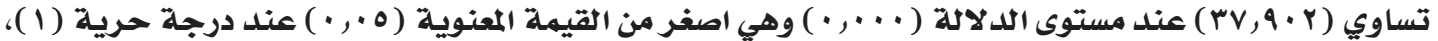

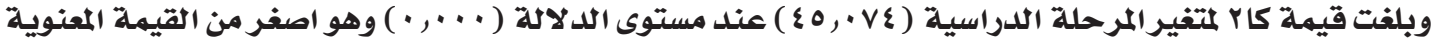

(0. (• ) ) عند درجة حرية ( ) ).

جدول ( r ا ) يبين وجود فروق دالة بين المتغيرات الديموغرافية للعينة نحو المشاركة ِِّ الاعمال التطوعية

\begin{tabular}{|c|c|c|c|c|c|}
\hline نوع العلاقة & مستوى المعنوية & مستوى الدلالة & درجة الحرية & قيمة اختبار كاr & التفاصيل \\
\hline دالة &., .0 & $\cdot, \ldots$ & 1 & \& & النوع \\
\hline دالة &., .0 & r & r & $v, 0 \leqslant$. & العمر \\
\hline دالة &., .0 &,$\ldots$ & 1 & $r v, q \cdot r$ & التخصص \\
\hline دالة &., .0 &,$\ldots$ & $\varepsilon$ & $\varepsilon 0, \cdot v \varepsilon$ & المرحلة الدراسية \\
\hline
\end{tabular}

Y- توجد علاقة ارتباط دالة بين المتغيرات الديموغرافية للعينة وتأثير القنوات الفضائية ِِِ اتجاها تها 
يتضح من جلول (عأ) أ) وجود علاقة ارتباط دالة بين المتغيرات الديموغرافية للعينة وتأثير القنوات

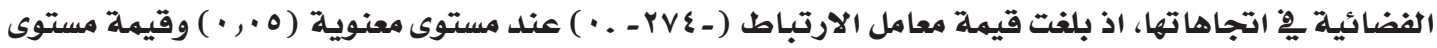

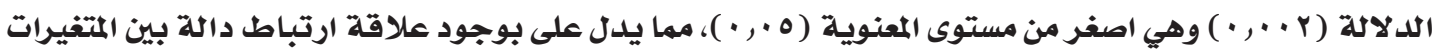

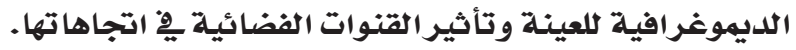

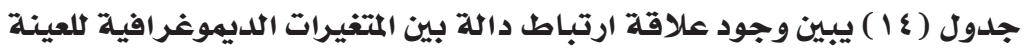

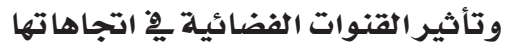

\begin{tabular}{|c|c|c|c|}
\hline مستوى العلاقة & مستوى المعنوية & مستوى الدلالة p-value & قيهة معامل ارتباط بيرسون \\
\hline | - دالة &., .0 & $\cdot, \cdots r$ & $\cdot .-r v \varepsilon-$ \\
\hline
\end{tabular}

بـ توجد علاقة ارتباط دالة بين مشاهدة برامج القنوات الفضائية وادراك ثقافة العمل التطوعي لدى العينة يتضح من جدول ( 10 ) وجود علاقة ارتباط دالة بين مشاهدة برامج القنوات الفضائية وادراك ثقافة العمل

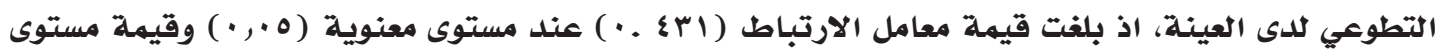

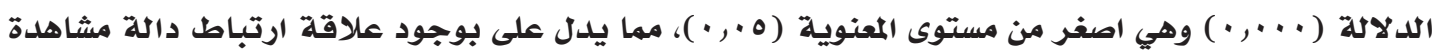

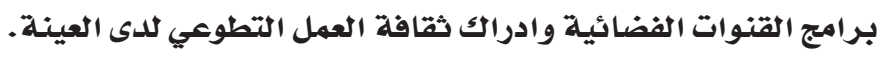

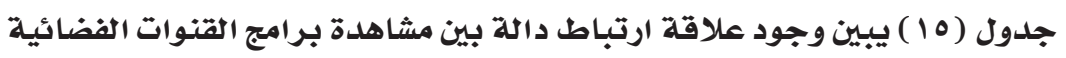

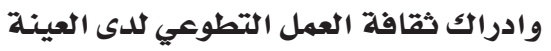

\begin{tabular}{|c|c|c|c|}
\hline مستوى العلاقة & مستوى المعنوية & مستوى الدلالة p-value & قيمة معامل ارتباط بيرسون \\
\hline دالة & $\cdot, .0$ &,$\ldots$ & ו \\
\hline
\end{tabular}

النتائج والاستنتاجات

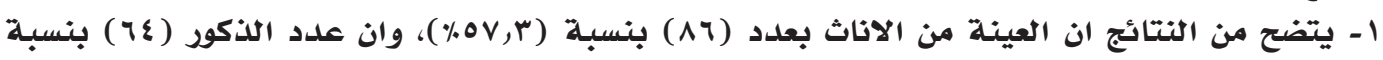
.$(\% \varepsilon r, V)$

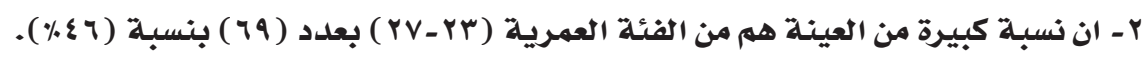

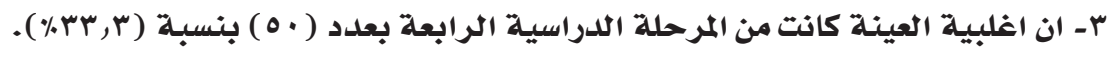

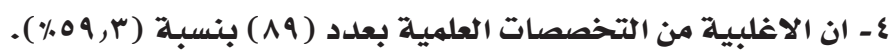

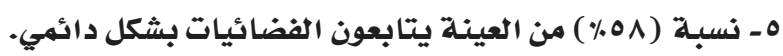

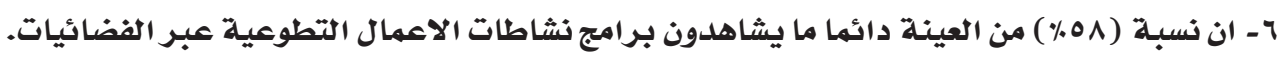

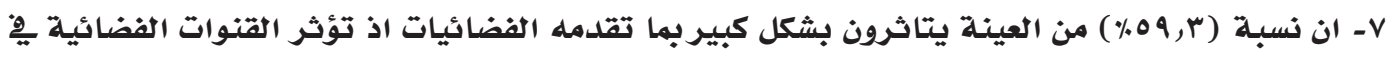
اتجاها تهم. ^- نسبة ( (9٪) من العينة لديهم معرفة بمفهوم ثقافة العمل التطوعي بانها اعمال ونشاطات لا تهدف الى الى تحقيق الربح.

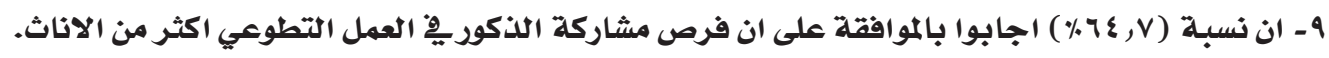

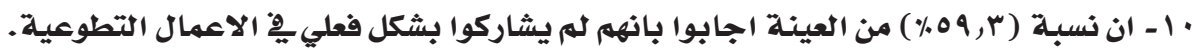

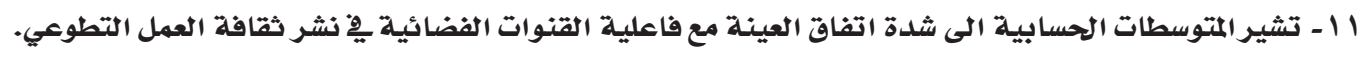

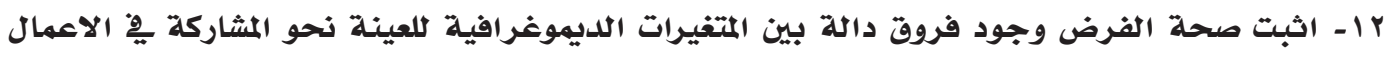
التطوعية. با - اثبت صحة الفرض وجود علدة علاقة ارتباط دالة بين المتغيرات الديموغرافية للعينة وتأثير القنوات

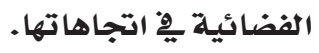




\section{ع ا - اثبت صحة الفرض وجود علاقة ارتباط دالة بين مشاهدة برامج القنوات الفضائية وادراك ثقافة العهل التطوعي لدى العينة.

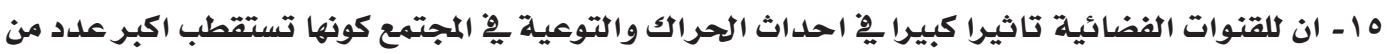

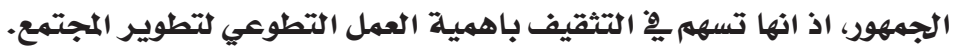 التوصيات}

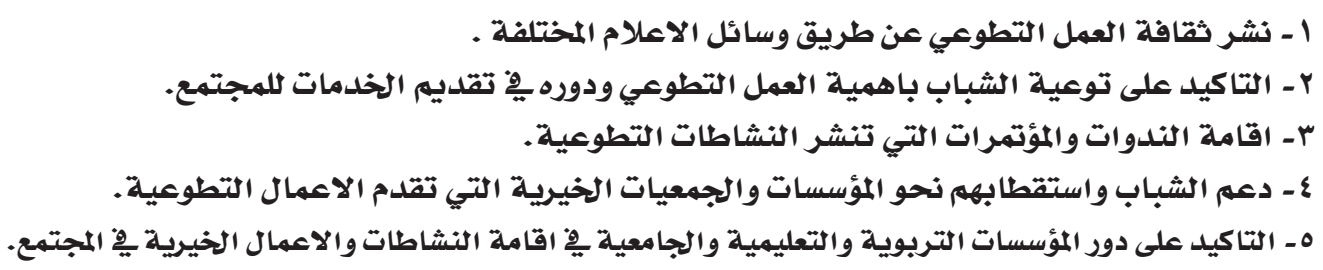

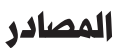

Ibn Manzoor, (1996), Sanson Al Arab, I 1, House of Revival of Arab Heritage Foundation o f Arab History, .1 .Beirut

Aboud, Mohamed Ahmed Mohamed, (2008), Role of Egyptian Television Series in Prioritizing Social Issues .2 among Adolescents: Applied Study, Master Thesis, Cairo, Institute of Graduate Studies for Children, Ain Shams .University, p.6

Al-Juhani, manee Hammad, (2010), Role of Institutions in Voluntary Service in Saudi Arabia, The First Scientific .3 .Conference of Voluntary Work in Saudi Arabia, Umm Al-Qura, Makkah

Hijab, Muhammad Munir, (2010), Theories of Communication, Cairo, Dar Al Fajr Publishing and Distribution, .4 .p. 306

Hussein, Ibrahim, (2001), Voluntary Work in a Global Perspective, Second Volunteer Conference, Sharjah (23-24 .5 .(January

Khawla, Hamaideya, (2015), The role of social networking sites in the development of voluntary work. An ana- .6 lytical descriptive study of the Facebook page of Nass Al-Khair and Argla Association, Master of Science, Depart.ment of Information and Communication Sciences, Faculty of Humanities and Social Sciences, 44

.Makkawi, Hassan Imad, Al-Sharif, Sami, Theories of Media, Cairo, Cairo University Center, 2000, pp. 112-114 .7 Al-Maliki, Samar Bint Mohammed bin Garmallah, (2012), the extent of awareness of post graduate students .8 at Umm Al-Qura University for the fields of volunteer work for women in the Saudi society "field study", Master .Thesis, Department of Islamic and Comparative Education. Umm al-Qura .Al-Munajjid in the Language, (1975), I (26), Orient House, Beirut .9

Al-Naim, Abdullah Al-Ali, (1999), Voluntary Social Work with a Focus on Volunteerism in Saudi Arabia, The .10 .Arab Journal, No. 21

.AL-Saate, Samia, (2003), Arab Youth and Social Change, Cairo, The Egyptian Lebanese Library, p.15 .11

Shahab Alddeen, Muhammad Fawzi, (2017), The role of television in prioritizing political issues among the .12 .Bahraini public, Series of Studies, Bahrain, Bahrain Institute for Political Development, pp. 59-60

AL-Shahwan, Mohammed Ahmad Qablan, (2017), The Role of Jordanian Television in the Development of .13 Volunteering from the Youth Perspective, "Jordan Youth Association Model", Master's Thesis, Faculty of Informa.tion, Middle East University, p.27

AL-Shahrani, Ma'lawi bin Abdullah, (2016), volunteer work and its relationship to the security of society: field .14 .study, Master Thesis, Graduate School, Department of Social Sciences, p.10

AL-Zair, Amna Bint Ahmed, (2015), Mekbel, Masha'al bint Fahad, volunteer work and values of citizenship .15 .among the Saudi youth field study applied to a sample of volunteers in Saudi Arabia, Riyadh, King Saud University

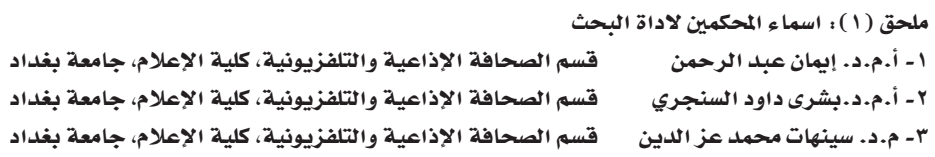

